\title{
Long-term stability of angle-stable versus conventional locked intramedullary nails in distal tibia fractures
}

\author{
Dirk Wähnert ${ }^{1,2^{*}}$, Yves Stolarczyk ${ }^{1}$, Konrad L Hoffmeier ${ }^{1}$, Michael J Raschke ${ }^{2}$, Gunther O Hofmann ${ }^{1,3}$ \\ and Thomas Mückley ${ }^{1}$
}

\begin{abstract}
Background: In the last years intramedullary nailing has become the treatment of choice for most displaced diaphyseal tibia fractures. In contrast intramedullary nailing of distal tibia fractures is accompanied by problems like decreased biomechanical stability. Nevertheless the indications for intramedullary nailing have been extended to include even more distal fractures. The purpose of this study was to compare long-term mechanical characteristics of angle-stable versus conventional locked intramedullary nails in the treatment of unstable distal tibia fractures. Therefore, the effect of time on the mechanical properties of biodegradable sleeves was assessed.

Methods: 8 pairs of fresh, frozen porcine tibiae were used. The expert tibial nail (Synthes) was equipped with either three conventional locking screws (CL) or the angle-stable locking system (AS), consisting of a special ASLS screw and a biodegradable sleeve. Biomechanical testing included torsional and axial loading at different time-points over 12 weeks.

Results: The AS group showed a significantly higher torsional stiffness at all time-points (at least 60\%) compared to the $C L$ group $(p<0.001)$. The neutral zone was at least 5 times higher in the $C L$ group $(p<0.001)$. The mean axial stiffness was maximum 10\% higher (week 6) in the angle-stable locked group compared to the conventional group. There was no significant change of the torsional mechanical characteristics over the 12 weeks in both groups $(p>0.05)$. For axial stiffness and range of motion significant differences were found in the AS group.

Conclusions: The angle-stable locking system (ASLS) with the biodegradable sleeve provides significantly higher long-term stability. Especially the differences determined under torsional loading in this study may have clinical relevance. The ASLS permits the potential to decrease complications like secondary loss of reduction and mal-/non-union.
\end{abstract}

Keywords: Distal tibia fractures, Angular stability, Intramedullary nailing, ASLS, Biomechanics, Long-term

\section{Background}

In modern trauma care the treatment of unstable distal tibia fractures is still challenging. In the last years intramedullary nailing has become the treatment of choice for most displaced diaphyseal tibia fractures, because it provides a high mechanical stability and can be performed in a minimally invasive manner [1-7].

\footnotetext{
* Correspondence: Dirk.Waehnert@ukmuenster.de

'Department of Trauma-, Hand- and Reconstructive Surgery, Friedrich Schiller University Jena, Erlanger Allee 101, Jena 07747, Germany

${ }^{2}$ Department of Trauma-, Hand- and Reconstructive Surgery, University

Hospital Münster, Waldeyerstr. 1, Münster 48149, Germany

Full list of author information is available at the end of the article
}

Compared to diaphyseal fractures intramedullary nailing of distal tibia fractures is accompanied by problems like decreased biomechanical stability due to the anatomical conditions of the distal tibia $[8,9]$. The difference in size between the implant diameter and the metaphyseal diameter results in small nail-cortex contact. Additionally the diminished cortical bone support of the distal tibia limits the construct stability [10]. Nevertheless the indications of intramedullary nailing have been extended to include even more distal fractures $[9,11]$. Consequently, fractures of the distal one third of the tibia treated with intramedullary nailing frequently 
result in varus, valgus, or torsional deformities and nonunions [12-16].

To improve the construct stability of intramedullary nailed distal tibia fractures, recently, angle-stable interlocking screws encased by a sleeve have been introduced. First using a PEEK (polyetheretherketone) sleeve, the manufacturer completely changed the sleeve material to biodegradable 70:30 poly(L-lactide-co-D,L-lactide). In a previous study our group could already show the significant increase of initial torsional stability due to angle-stable locking [17].

The purpose of this study was to assess the long-term biomechanical fixation characteristics of the angle-stable locking system using the new biodegradable sleeve.

\section{Methods}

The protocol used in this study was based on the publication of Wähnert et al. [17].

\section{Specimens}

For this study eight pairs of fresh frozen porcine tibiae (all female, all same age) were used (bought at the Slaughterhouse Jena, Germany). Specimens were frozen, stored at $-20^{\circ} \mathrm{C}$, and thawed at room temperature 24 hours before potting and mechanical testing. Within each pair, one tibia was randomized to receive angle-stable locking (group I - AS), whereas the contralateral tibia received conventional locking (group II - CL). Before testing, specimens were completely stripped of soft tissues and a transverse osteotomy was performed $5.5 \mathrm{~cm}$ proximal to the tibiotalar joint line (Figure 1A).

\section{Implants}

The $8 \mathrm{~mm}$ cannulated expert tibial nail (Synthes $\mathrm{GmbH}$, Solothurn, Switzerland) with according locking screws was used (Figure 1B). All nails were cut $20 \mathrm{~cm}$ above the distal end. Proximally they were embedded over a length of $5 \mathrm{~cm}$ in two component cast resin (RenCast FC 52; Huntsman Advanced Materials, Monthey, Switzerland). An additional hole in antero-posterior direction has been drilled $13 \mathrm{~cm}$ proximal to the nail tip to connect the nail to a custom made drill guide jig.

For locking in both groups the three most distal screw holes were used as follows: distal screw from anterolateral to postero-medial, middle screw from medial to lateral and proximal screw from anterior to posterior (Figure 1C). In group I (AS) special $4 \mathrm{~mm}$ ASLS screws were used with the corresponding $4 \mathrm{~mm}$ ASLS sleeve. In group II (CL) $4 \mathrm{~mm}$ standard locking screws were used. All screws were chosen in appropriate length for a bicortical purchase.

\section{Instrumentation}

The nail was tapped into the unreamed distal tibia part to a distance of $15 \mathrm{~mm}$ from the distal articular surface. The position of the nail was checked using an image intensifier. Afterwards the distal locking was performed using a custom made drill guide to ensure standardized distal locking (Figure 2). The locking procedure followed the manufacturer's surgical technique and all steps were checked with the image intensifier.

Before distal embedding all exposed implant surfaces were covered with modeling compound to prevent direct
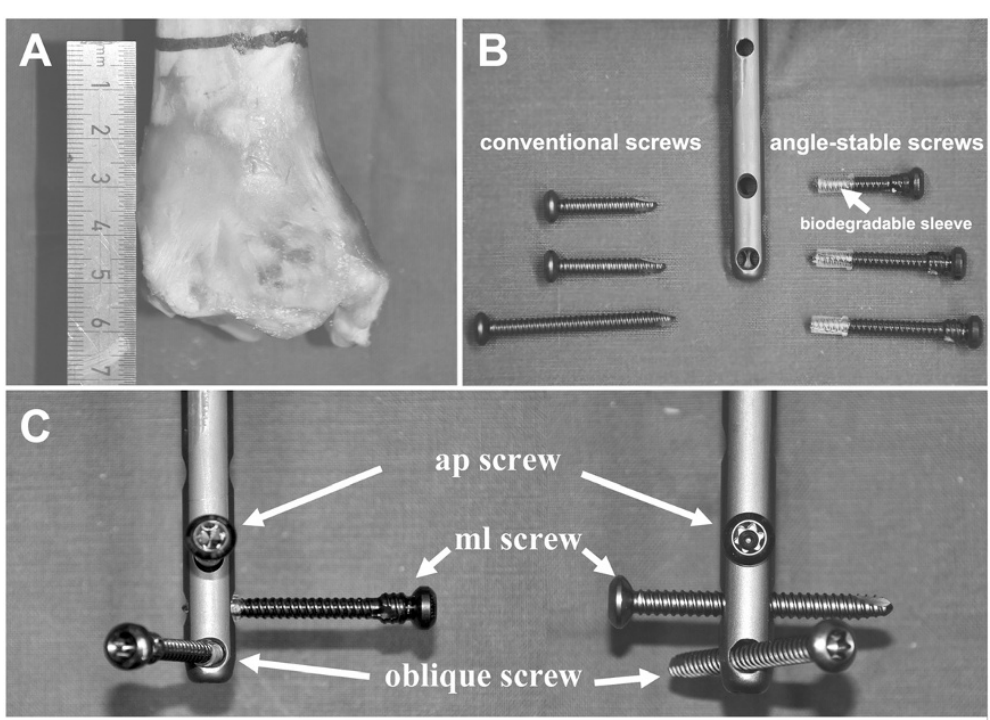

angular stable locking

conventional locking

Figure 1 (A) Porcine tibia with osteotomy $5.5 \mathrm{~cm}$ proximal to the tibiotalar joint line indicated; (B) cannulated Expert Tibial Nail with according locking screws (conventional - left, angle-stable with sleeves (arrow) preassembled - right); (C) Screw configuration used in this study with three screws for distal locking (ap = antero-posterior, $\mathrm{ml}=$ medio-lateral, oblique $=$ antero-lateral to postero-medial). 


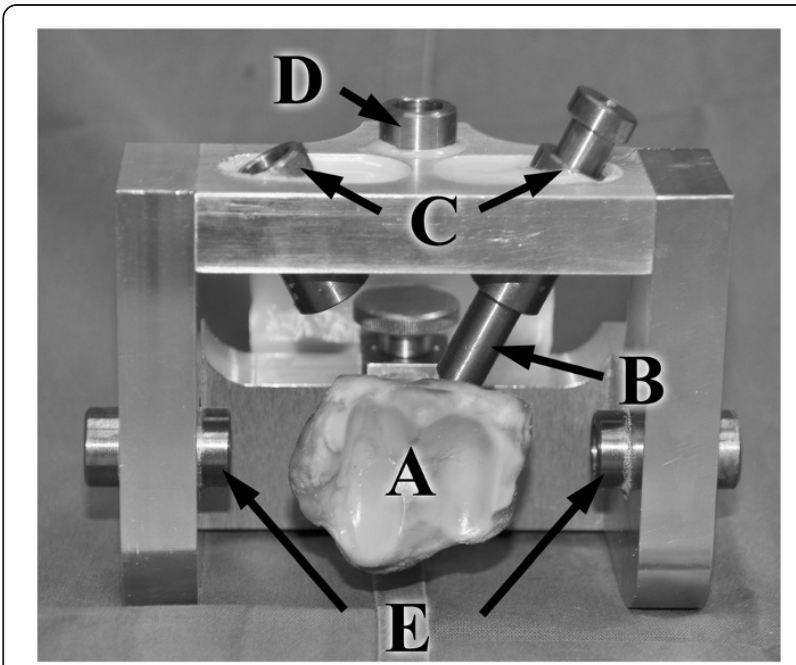

Figure 2 Distal locking using the custom made locking jig. A) specimen, B) drill sleeve, C) oblique drill guides, D) anterior-posterior drill guide, E) medial drill guides. Following nail insertion the construct was fixed to the jig and standardized drilling and locking could be performed (for left and right tibiae).

contact with the two component cast resin. A custom made jig was used for both, distal and proximal embedding to ensure a central nail position. Thus torsional loading without any bending was assured.

\section{Mechanical testing}

Quasi-static mechanical testing was performed on a servo-hydraulic testing machine (Instron 8874, Instron, High Wycombe, Bucks, United Kingdom) (Figure 3).

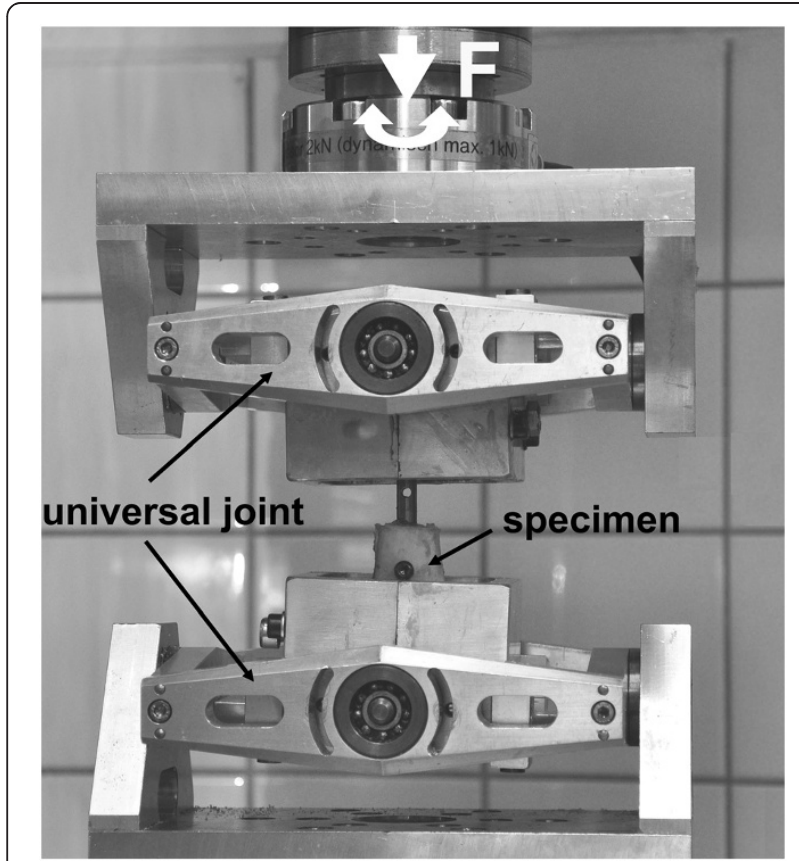

Figure 3 Test setup for axial and torsional testing.
Axial and torsional testing was performed subsequently, starting with torsional loading. The specimens were loaded with $5 \mathrm{Nm}$ in external and internal rotation for 10 cycles with a crosshead speed of $1 \mathrm{Nm} / \mathrm{s}$. Followed by axial loading with a preload of $5 \mathrm{~N}$ and a crosshead speed of $1 \mathrm{~mm} / \mathrm{min}$ to a maximum load of $50 \mathrm{~N}$ (tension and compression) for 10 cycles. The loads were chosen to ensure deformation in the elastic range only without damaging the bone implant construct. This protocol was performed for all specimens after instrumentation and was subsequently repeated after four, six, eight and twelve weeks.

\section{Storage}

In between the tests the specimens including the potting and the implants underwent immersion in phosphatebuffered saline (PBS). The temperature (37 degrees $\mathrm{C}$ ) and the $\mathrm{pH}$ (7.4) were kept constant throughout the period of immersion [18].

\section{Data acquisition and evaluation}

Time, load, displacement, torsional moment, angle and cycle number were acquired and plotted with use of MAX software (version 9.2; Instron, Canton, Massachusetts). Using the load displacement curves axial and tosional stiffness, range of Motion (ROM) and the torsional neutral zone (NZ) were determined following Wilke et al. [19]. Statistical analyses were performed using SPSS for Windows (Version 16, SPSS Inc., Chicago). After assessing data distribution using the Shapiro-Wilk test, significant differences between the groups were identified and analysed using one-way ANOVA (with Bonferroni correction) statistics. Significance level was set to $\alpha=0.05$.

\section{Results}

Torsional

For torsional stiffness the angle-stable group also showed significantly higher values at all time-points $(\mathrm{p}<0.01)$. Additionally there was no significant change of the torsional stiffness over time within the groups (AS $\mathrm{p}>0.97$, CL $\mathrm{p}>0.74$, Figure 4).

The torsional ROM was significantly lower for the angle-stable locked group at any time-points compared to the conventional locked specimens ( $p<0.01$; Figure 5). For the conventional group the ROM was approximately $70 \%$ larger compared to the angle-stable. There was no significant change of the ROM comparing the different time-points in both groups (AS p >0.98, CL p > 0.82).

The neutral zone was significantly lower for the anglestable locked construct at all time-points measured $(\mathrm{p}<0.01$, Figure 6$)$. The conventional locked group had a 5 to 6 times larger neutral zone compared to the angle-stable. For the angle-stable and the conventional 


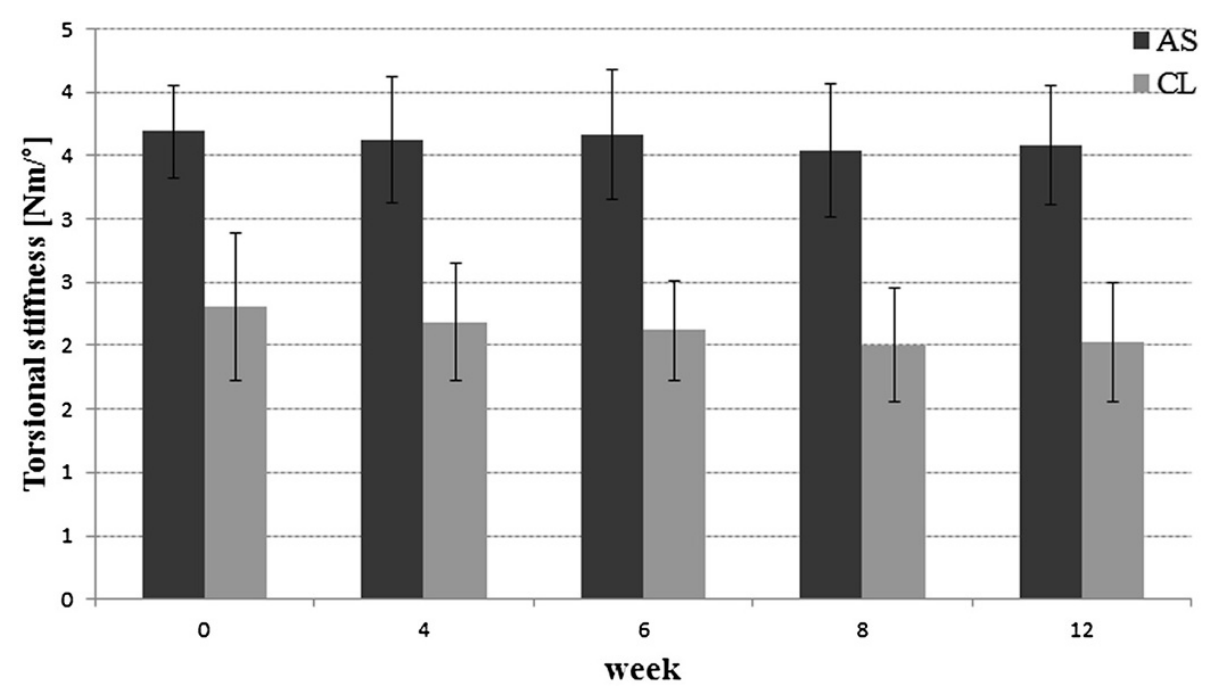

Figure 4 Diagram showing the mean torsional stiffness $\left[\mathrm{Nm} /{ }^{\circ}\right]$ for all measured time-points for the angle-stable and conventional constructs with the standard deviation.

group there was no significant change comparing the different time-points (AS p >0.33, CL p > 0.97).

\section{Axial}

The mean axial stiffness was maximum 10\% higher (week 6) in the angle-stable locked group compared to the conventional group. Statistical this difference was significant for week 6,8 and $12(p<0.02$, Figure 7$)$. Comparing week 0 and 4 there was no significance found $(p>0.14)$. Within the angular-stable group there was a significant increase of stiffness comparing week 0 and 6 $(\mathrm{p}=0.024)$ and week 0 and $8(\mathrm{p}=0.021)$. The conventional group showed no significant change comparing the different time-points $(\mathrm{p}>0.06)$.

The mean axial range of motion was higher for the conventional locked group (maximum 14\% in week 0). Statistically significant difference was only found for week $8(p=0.019$, Figure 8$)$. Within the angular-stable group there was a significant difference comparing week 0 and $6(\mathrm{p}=0.021)$ and week 0 and $8(\mathrm{p}=0.013)$. The

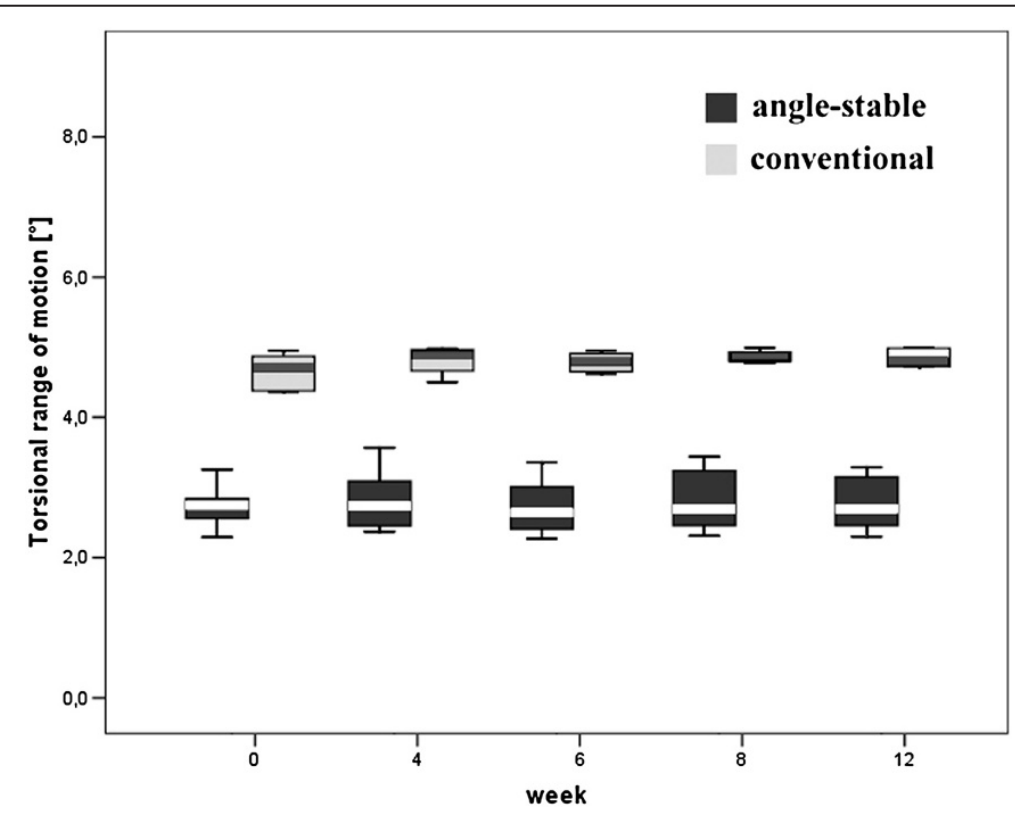

Figure 5 Box plot of the torsional range of motion [ $\left.{ }^{\circ}\right]$ for the angle-stable and the conventional group. 


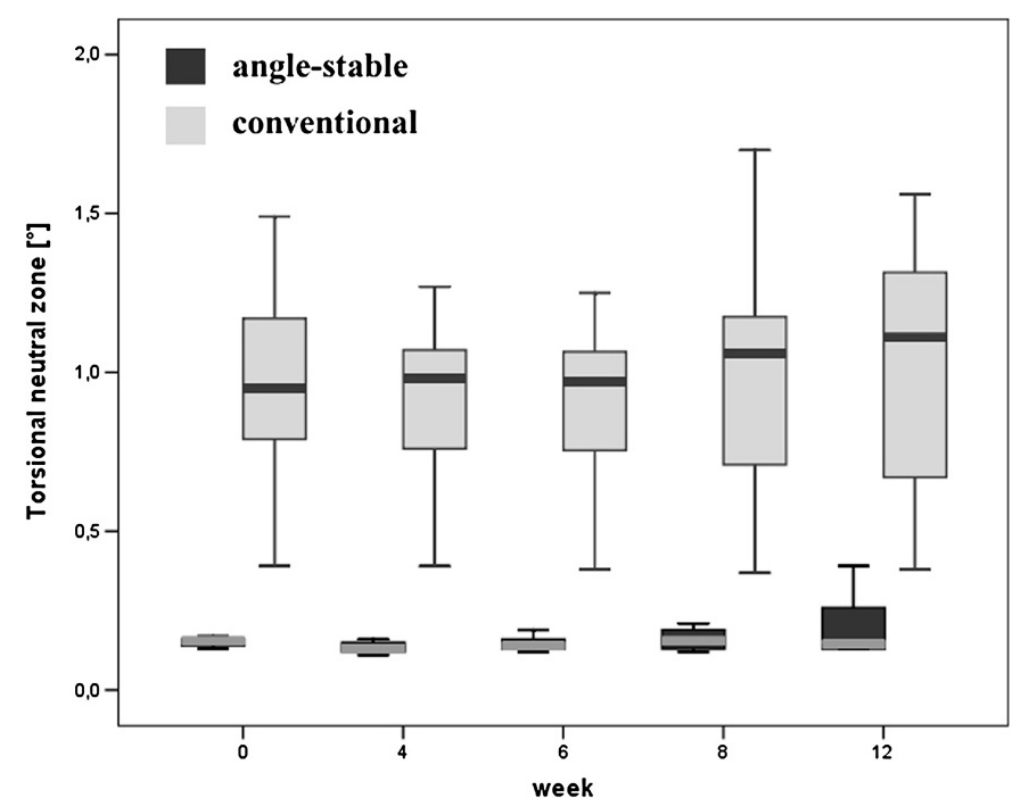

Figure 6 Box plot showing the torsional neutral zone $\left[^{\circ}\right]$ for all measured time-points for the angle-stable and conventional constructs.

conventional group showed significant differences comparing week 0 and $4(\mathrm{p}=0.04)$ and week 0 and $8(\mathrm{p}=0.03)$.

\section{Discussion}

This study was performed to investigate the long-term mechanical fixation stability of the angle-stable locking system using the new biodegradable sleeve in the treatment of distal tibia fractures fixed with IM nailing. Angle-stable locking results in a significant increase in torsional fixation stability including a significant reduction of the neutral zone, range of motion and increase of stiffness compared to conventional locking. Additionally the torsional stability showed no significant change over 12 weeks within both groups. For axial loading angle-stable locking had a less powerful impact on stability including stiffness and range of motion. Axial stiffness was significantly higher for the angle-stable group starting from week 6 .

Intramedullary nailing of tibia fractures is an accepted and widely used treatment option. In the past few years this method has been used to address even more distal tibia fractures. This extension of the indications goes along with a growing number of reported complications such as delayed healing, nonunion, coronal plane and rotational malalignment/malunion [9,16,20-23].

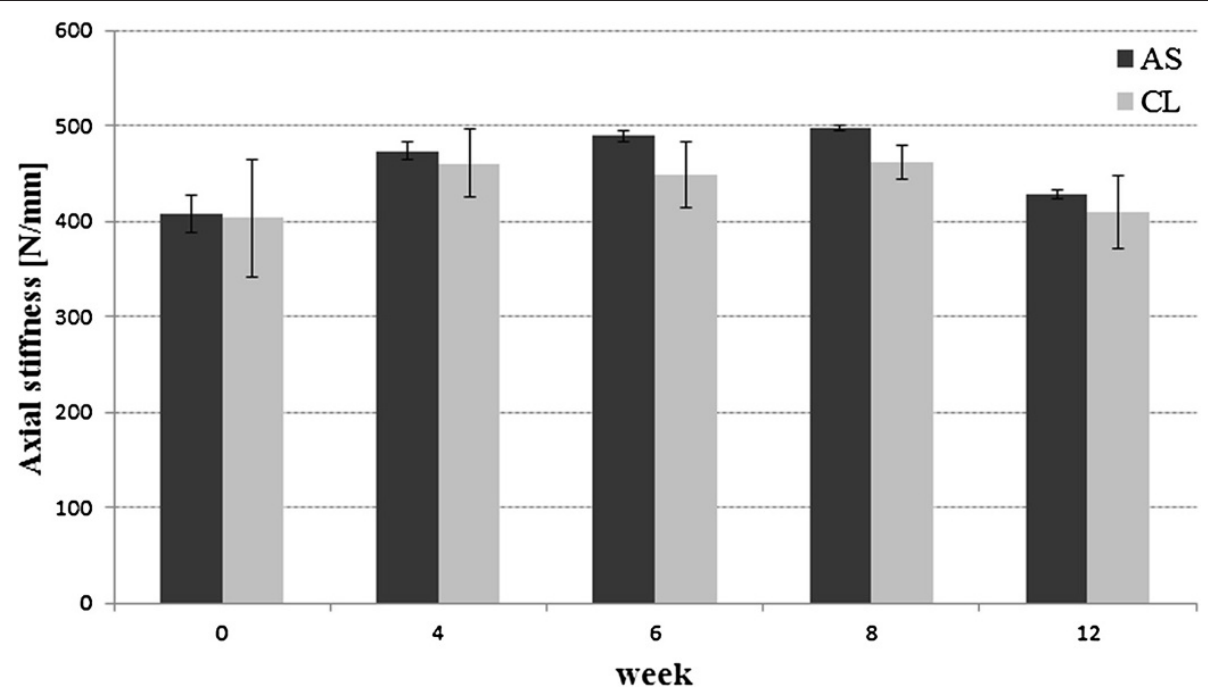

Figure 7 Diagram showing mean axial stiffness $[\mathrm{N} / \mathrm{mm}]$ with standard deviation for both groups and all time-points. 


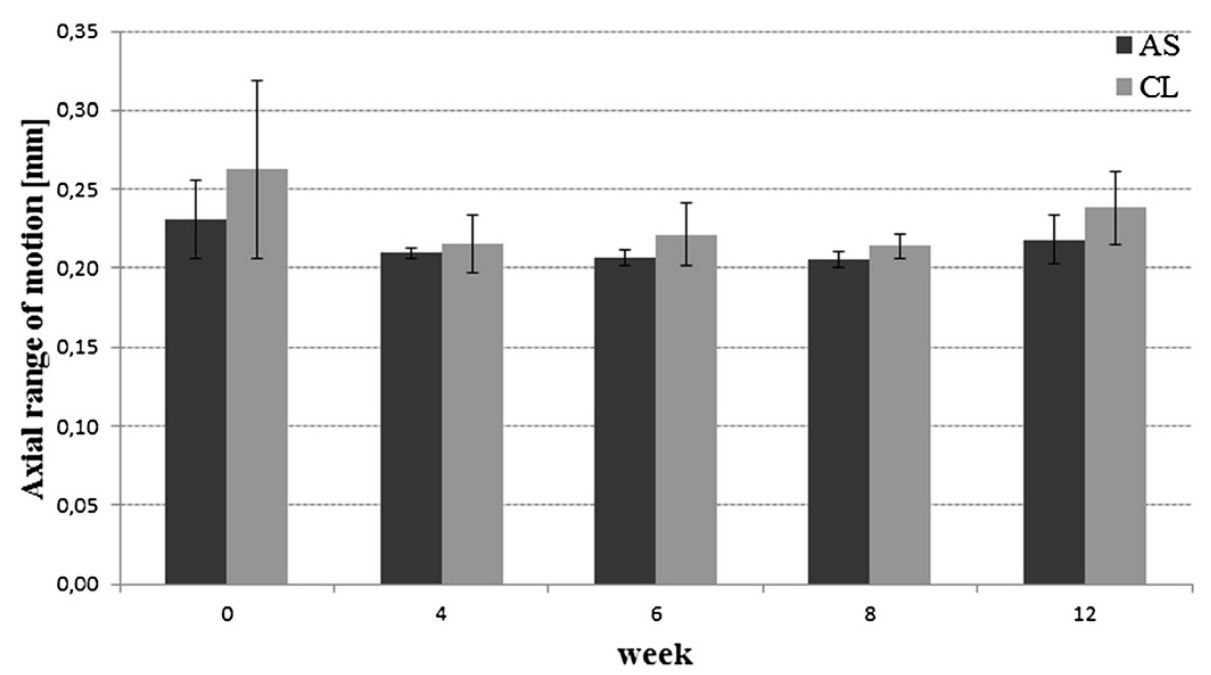

Figure 8 Diagram showing mean axial range of motion with standard deviation for both groups.

Various modifications and new developments of implants have been introduced to reduce the complications and make the benefits of intramedullary nailing applicable even in these distal tibia fractures. First of all the number and the sites of the distal locking holes were adapted to the pattern of very distal tibia fractures. In biomechanical and clinical studies shortened tibia nails showed comparable biomechanical stability and good clinical results compared to standard nails $[24,25]$. Modern intramedullary tibia nails allow distal locking using up to four screws.

One novel approach to the problems of distal tibia fracture management is the angle-stable locking of intramedullary nails with use of a preassembled 70:30 poly(L-lactide-co-D,L-lactide) sleeve on ASLS locking screws. A few previous studies already investigated this technique using a PEEK (polyetheretherketone) sleeve. In summary these studies showed a significantly higher axial stiffness and significantly less fracture gap movement [26] and a significant reduction of the neutral zone in mediolateral bending for the angular-stable locked intramedullary nails [27]. A third study showed the potential of angle-stable locking to maintain fixation stability while reducing the number of locking screws in the treatment of unstable distal tibia fractures [28]. All these studies used the PEEK sleeves. In a former study our group already investigated the primary biomechanical fixation stability of the new biodegradable sleeve. In this study we found the angle-stable locked constructs providing a significantly higher torsional and axial primary stability compared to conventional locking [17]. In the present study we could affirm the advantage of the angle-stable locking especially for torsional fixation stability over a time of 12 weeks. In an in vivo study using tibia midshaft fractures in sheep Epari et al. could show the negative influence of torsional and sheer stresses on fracture healing [29]. Additionally the group of Kaspar et al. found angle-stable locking of intramedullary nails in tibia fractures to result in less fracture gap movement and better radiologic, histomorphometric, biomechanical and clinical fracture healing in sheep [30]. Therefore angle-stable locking of intramedullary nails seemed to be an option to reduce the risk of delayed union and, because of the increased stability, of secondary loss of reduction. Thus, this procedure potentially provides an option to use intramedullary nailing in even distal tibia fractures and osteoporotic fractures.

One concern about the use of biodegradable implants is an inflammatory reaction (seen after medial malleolus fixation). The system is available since 2009 and, to the knowledge of the authors until now no case of inflammation or problems in wound healing have been reported. The sleeve degrades to lactic acid; the degradation speed depends on the location of the sleeve and patient characteristics. The manufacturer (Synthes, Solothurn, Switzerland) guaranteed mechanical characteristics for four weeks. We have chosen the timepoints for mechanical measurements from a clinical point of view, the healing process of a tibia fracture treated with an intramedullary nail can take up to 3 month (12 weeks). The huge differences between the sleeve and implants used for medial malleolus fixation are the small amount of material of the sleeve and the total intramedullary and nearly complete intra-nail location of the sleeve. This results in a very small interaction area between human body and biodegradable sleeve.

This study has limitations. First, the use of porcine bone, this material is widely used for biomechanical testing due to its availability [31], for example the knee and spine [32-35]. From these investigations we know that the bone mineral density of the porcine tibia is higher than human [36,37]. For the interpretation of the 
results we have to take into account that we do not have an osteoporotic bone model. But the advantage of increased stability of the angle-stable locking is due to decreased screw-nail movement and will also be present in osteoporotic bone. Also the number of specimens was small, but it was high enough to show significant differences between the groups. Furthermore, the standard deviation in the AS group was very small. In the CL group it was clearly higher; this may be caused by the locking procedure: if the locking bolts are not placed ideal perpendicular and central in the locking hole they block the bone implant construct and a higher mechanical stability results. Such variables confound the results, but we tried to reduce them e.g. by standardized locking using a custom made drill and locking jig. Second, we used a "hydrolysis chamber" with standardized temperature and $\mathrm{pH}$ to simulate physiologic conditions. Although we know this is a model, it is a well-established way to simulate the in-vivo absorption (hydrolysis) of polylactidpolymers [38-42]. Furthermore, loading conditions have been chosen to allow subsequent torsional and axial loading over 12 weeks without causing plastic deformation due to testing. Thus biomechanical loading in this study does not represent physiologic conditions. Additional biomechanical studies investigating the biodegradable sleeve under physiologic loading have to be performed.

Clinical studies will be required to investigate the utility of the technique in the management of these difficult to treat distal tibia fractures and to show the benefit in patient care.

\section{Conclusion}

The angle-stable locking system (ASLS) using a special screw and sleeve locking for intramedullary nails provides significantly higher long-term fixation stability. Especially in torsional loading the differences determined in this biomechanical study may have clinical relevance. We also found differences between the groups for the axial stability, but we think the magnitude is not that relevant for clinical application. From the mechanical point of view this system has the potential to decrease complications like secondary loss of reduction and mal-/non-union. Clinical studies have to confirm these results.

\section{Competing interest}

All authors disclose any financial and personal relationships with other people or organisations that could inappropriately influence (bias) this work. The material was kindly supplied by the manufacturer Synthes.

\section{Authors' contributions}

DW was involved in planning the study, assisted during the tests, did the data analysis and wrote the manuscript. YS and $\mathrm{KH}$ did the instrumentation, performed the tests and collected the data. Additionally $\mathrm{KH}$ was involved in the statistical analysis. MR was involved in writing the manuscript and data analysis. GH and TM were involved in planning the study and writing/ revising the manuscript and provide supervision. All authors read and approved the final manuscript.

\section{Acknowledgments}

All implant materials (nails, screws and sleeves) were supplied by the manufacturer Synthes (Solothurn, Switzerland). There was no additional influence on any part of the study by Synthes.

We acknowledge support by Deutsche Forschungsgemeinschaft and Open Access Publication Fund of University of Muenster.

\section{Author details}

'Department of Trauma-, Hand- and Reconstructive Surgery, Friedrich Schiller University Jena, Erlanger Allee 101, Jena 07747, Germany. ${ }^{2}$ Department of Trauma-, Hand- and Reconstructive Surgery, University Hospital Münster, Waldeyerstr. 1, Münster 48149, Germany. ${ }^{3}$ BG-Kliniken Bergmannstrost Halle, Department of Trauma- and Reconstructive Surgery, Merseburger Str. 165, Halle 06112, Germany.

Received: 1 June 2012 Accepted: 19 February 2013

Published: 20 February 2013

\section{References}

1. Alho A, Ekeland A, Stromsoe K, Folleras G, Thoresen BO: Locked intramedullary nailing for displaced tibial shaft fractures. J Bone Joint Surg Br 1990, 72:805-809.

2. Bone $L B$, Johnson $K D$ : Treatment of tibial fractures by reaming and intramedullary nailing. J Bone Joint Surg Am 1986, 68:877-887.

3. Collins DN, Pearce CE, McAndrew MP: Successful use of reaming and intramedullary nailing of the tibia. J Orthop Trauma 1990, 4:315-322.

4. Court-Brown CM: Reamed intramedullary tibial nailing: an overview and analysis of 1106 cases. J Orthop Trauma 2004, 18:96-101.

5. Court-Brown CM, Christie J, McQueen MM: Closed intramedullary tibial nailing. Its use in closed and type I open fractures. $J$ Bone Joint Surg Br 1990, 72:605-611.

6. Tornetta P 3rd, Bergman M, Watnik N, Berkowitz G, Steuer J: Treatment of gradeIIIb open tibial fractures. A prospective randomised comparison of external fixation and non-reamed locked nailing. J Bone Joint Surg Br 1994, 76:13-19.

7. Whittle AP, Russell TA, Taylor JC, Lavelle DG: Treatment of open fractures of the tibial shaft with the use of interlocking nailing without reaming. J Bone Joint Surg Am 1992, 74:1162-1171.

8. Bedi A, Le TT, Karunakar MA: Surgical treatment of nonarticular distal tibia fractures. J Am Acad Orthop Surg 2006, 14:406-416.

9. Kuhn S, Hansen M, Rommens PM: Extending the indications of intramedullary nailing with the Expert Tibial Nail. Acta Chir Orthop Traumatol Cech 2008, 75:77-87.

10. Papadakis SA, Segkos D, Katsiva V, Panagiota P, Balanika A, Stavrianos V, Mpalia I, Katonis P: Intramedullary bone formation after intramedullary nailing. J Orthop Trauma 2009, 23:288-293.

11. Duda GN, Mandruzzato F, Heller M, Schutz M, Claes L, Haas NP: [Mechanical borderline indications in the treatment of unreamed tibial nailing]. Unfallchirurg 2003, 106:683-689.

12. Bhandari M, Guyatt $G H$, Swiontkowski MF, Schemitsch EH: Treatment of open fractures of the shaft of the tibia. J Bone Joint Surg Br 2001, 83:62-68.

13. Bilat C, Leutenegger A, Ruedi T: Osteosynthesis of 245 tibial shaft fractures: early and late complications. Injury 1994, 25:349-358.

14. Court-Brown CM, McBirnie J: The epidemiology of tibial fractures. J Bone Joint Surg Br 1995, 77:417-421.

15. Drosos G, Karnezis IA, Bishay M, Miles AW: Initial rotational stability of distal tibial fractures nailed without proximal locking: the importance of fracture type and degree of cortical contact. Injury 2001, 32:137-143.

16. Kahn KM, Beals RK: Malrotation after locked intramedullary tibial nailing: three case reports and review of the literature. J Trauma 2002, 53:549-552.

17. Wahnert D, Stolarczyk Y, Hoffmeier KL, Raschke MJ, Hofmann GO, Muckley T: The primary stability of angle-stable versus conventional locked intramedullary nails. Int Orthop 2012, 36:1059-1064.

18. Klos K, Sauer S, Hoffmeier K, Gras F, Frober R, Hofmann GO, Muckley T: Biomechanical evaluation of plate osteosynthesis of distal fibula fractures with biodegradable devices. Foot Ankle Int 2009, 30:243-251.

19. Wilke $H J$, Wenger $K$, Claes L: Testing criteria for spinal implants: recommendations for the standardization of in vitro stability testing of spinal implants. Eur Spine J 1998, 7:148-154.

20. Im Gl, Tae SK: Distal metaphyseal fractures of tibia: a prospective randomized trial of closed reduction and intramedullary nail versus open reduction and plate and screws fixation. J Trauma 2005, 59:1219-1223. discussion 1223. 
21. Tyllianakis $M$, Megas $P$, Giannikas $D$, Lambiris $E$ : Interlocking intramedullary nailing in distal tibial fractures. Orthopedics 2000, 23:805-808.

22. Vallier HA, Le TT, Bedi A: Radiographic and clinical comparisons of distal tibia shaft fractures (4 to $11 \mathrm{~cm}$ proximal to the plafond): plating versus intramedullary nailing. J Orthop Trauma 2008, 22:307-311.

23. Zelle BA, Bhandari M, Espiritu M, Koval KJ, Zlowodzki M: Treatment of distal tibia fractures without articular involvement: a systematic review of 1125 fractures. J Orthop Trauma 2006, 20:76-79.

24. Gorczyca JT, McKale J, Pugh K, Pienkowski D: Modified tibial nails for treating distal tibia fractures. J Orthop Trauma 2002, 16:18-22.

25. Fan CY, Chiang CC, Chuang TY, Chiu FY, Chen TH: Interlocking nails for displaced metaphyseal fractures of the distal tibia. Injury 2005, 36:669-674.

26. Horn J, Linke B, JHöntzsch D, Gueorguiev B B, Schwieger K: Angle stable interlocking screws improve construct stability of intramedullary nailing of distal tibia fractures: a biomechanical study. Injury 2009, 40:767-771.

27. Gueorguiev B, Wahnert D, Albrecht D, Ockert B, Windolf M, Schwieger K: Effect on dynamic mechanical stability and interfragmentary movement of angle-stable locking of intramedullary nails in unstable distal tibia fractures: a biomechanical study. J Trauma 2011, 70:358-365.

28. Gueorguiev B, Ockert B, Schwieger K, Wahnert D, Lawson-Smith M, Windolf $M$, Stoffel $K$ : Angular stability potentially permits fewer locking screws compared with conventional locking in intramedullary nailed distal tibia fractures: a biomechanical study. J Orthop Trauma 2011, 25:340-346.

29. Epari DR, Kassi JP, Schell H, Duda GN: Timely fracture-healing requires optimization of axial fixation stability. J Bone Joint Surg Am 2007, 89:1575-1585.

30. Kaspar K, Schell H, Seebeck P, Thompson MS, Schutz M, Haas NP, Duda GN: Angle stable locking reduces interfragmentary movements and promotes healing after unreamed nailing. Study of a displaced osteotomy model in sheep tibiae. J Bone Joint Surg Am 2005, 87:2028-2037.

31. Bonney H, Colston BJ, Goodman AM: Regional variation in the mechanical properties of cortical bone from the porcine femur. Med Eng Phys 2011, 33:513-520.

32. Weimann A, Wolfert A, Zantop T, Eggers AK, Raschke M, Petersen W: Reducing the "killer turn" in posterior cruciate ligament reconstruction by fixation level and smoothing the tibial aperture. Arthroscopy 2007, 23:1 104-1111.

33. Lenschow S, Schliemann B, Dressler K, Zampogna B, Vasta S, Raschke M, Zantop $\mathrm{T}$ : Structural properties of a new fixation strategy in double bundle ACL reconstruction: the MiniShim. Arch Orthop Trauma Surg 2011, 131:1159-1165.

34. Spahn G, Muckley T, Kahl E, Hofmann GO: Biomechanical investigation of different internal fixations in medial opening-wedge high tibial osteotomy. Clin Biomech (Bristol, Avon) 2006, 21:272-278.

35. Kocis J, Navrat T, Florian Z, Wendsche P: Biomechanical testing of spinal segment fixed by thoracolumbar spine locking plate on the swine lumbar spine. Biomed Pap Med Fac Univ Palacky Olomouc Czech Repub 2010, 154:345-354.

36. Fuss FK: Anatomy and function of the cruciate ligaments of the domestic pig (Sus scrofa domestica): a comparison with human cruciates. J Anat 1991, 178:11-20.

37. Mariani PP, Margheritini F, Bellelli A: Bone mineral density of the proximal metaphysis of tibia: clinical relevance in posterior cruciate ligament reconstruction. Knee Surg Sports Traumatol Arthrosc 2005, 13:263-267.

38. Amsden BG, Tse MY, Turner ND, Knight DK, Pang SC: In vivo degradation behavior of photo-cross-linked star-poly(epsilon-caprolactone-co-D, L-lactide) elastomers. Biomacromolecules 2006, 7:365-372.

39. Bozic KJ, Perez LE, Wilson DR, Fitzgibbons PG, Jupiter JB: Mechanical testing of bioresorbable implants for use in metacarpal fracture fixation. J Hand Surg Am 2001, 26:755-761.

40. Farrar DF, Gillson RK: Hydrolytic degradation of polyglyconate B: the relationship between degradation time, strength and molecular weight. Biomaterials 2002, 23:3905-3912.

41. Mainil-Varlet P, Curtis R, Gogolewski S: Effect of in vivo and in vitro degradation on molecular and mechanical properties of various lowmolecular-weight polylactides. J Biomed Mater Res 1997, 36:360-380.

42. Proikakis CS, Mamouzelos NJ, Tarantili PA, Andreopoulos AG: Swelling and hydrolytic degradation of poly(D, L-lactic acid) in aqueous solutions. Polym Degrad Stabil 2006, 91:614-619.

doi:10.1186/1471-2474-14-66

Cite this article as: Wähnert et al:: Long-term stability of angle-stable versus conventional locked intramedullary nails in distal tibia fractures. BMC Musculoskeletal Disorders 2013 14:66.

\section{Submit your next manuscript to BioMed Central and take full advantage of:}

- Convenient online submission

- Thorough peer review

- No space constraints or color figure charges

- Immediate publication on acceptance

- Inclusion in PubMed, CAS, Scopus and Google Scholar

- Research which is freely available for redistribution 